\title{
Terceira idade: Características e Políticas Públicas Associadas
}

\author{
Ana Olívia de Oliveira Marinho ${ }^{(1)}$; Marianna Leite Barroso ${ }^{(2)}$; Gisanne de Oliveira Marinho $^{(3)}$
}

\begin{abstract}
Resumo: É notório o quanto o envelhecimento populacional vem crescendo graças à longevidade proporcionada pelos avanços da medicina. O envelhecimento é um fenômeno extremamente complexo, cujo conceito se deve a estrita interdependência dos aspectos biopsicosociais. Diversos estudos têm demonstrado uma associação entre envelhecimento e estados motivacionais depressivos. Embora se perceba uma melhora com relação à assistência aos idosos, associadas à uma maior participação dos mesmos em atividades voltadas para esta faixa etária e, a uma maior assistência por parte da implementação de diversos novos programas nas áreas assistenciais e de saúde, ainda é pequena a participação desses nos programas oferecidos. Sabemos que uma parcela significativa da população, principalmente no Nordeste do Brasil, encontra-se submetida a condições precárias de vida e, conseqüentemente, exposta a fatores de risco. Assim, a falta de atenção ao idoso e às suas problemáticas peculiares, parece ainda representar um problema de saúde pública no Brasil. Uma discussão sobre essa faixa etária e a efetividade de programas assistenciais para os mesmos, certamente ajudará na promoção de uma maior promoção de ações que considerem a melhoria do bem-estar desta parcela da população.
\end{abstract}

Palavras-Chave: Envelhecimento, Políticas públicas, Terceira idade

\section{Senior Adult: characteristics and public policy associated}

\begin{abstract}
It is notorious how the aging of the population is increasing thanks to the longevity provided by medical advances. Aging is an extremely complex phenomenon, whose concept is due to the close interdependence of the biopsychosocial aspects. Several studies have demonstrated an association between aging and depressive motivational states. Although an improvement with respect to the care of the elderly has been noticed, associated with a greater participation of the elderly in activities directed to this age group, and greater assistance from the implementation of several new programs in the areas of healthcare, it is still small the participation in these offered programs. We know that a significant portion of the population, especially in the Northeast of Brazil, is subjected to poor living conditions and consequently exposed to risk factors. Thus, the lack of attention to the elderly and their peculiar problems, seems to pose a public health problem in Brazil. A discussion about this age group and the effectiveness of welfare programs for them, will certainly help in fomenting a greater promotion of actions considering improviment of the well-being to this portion of the population.
\end{abstract}

Keywords: Aging, Public Politics, Senior Adult

\footnotetext{
1 Ana Olívia de Oliveira Marinho é Acadêmica de Medicina pela Universidade de Pernambuco - UPE. E-mail: fantinhapx@gmail.com;

${ }^{2}$ Marianna Leite Barroso é Enfermeira. Mestranda em Saúde pública pela Universidade Tecnológica Intercontinental - UTIC/PY. Email: mariannaleite_@hotmail.com;

${ }^{3}$ Gisane de Oliveira Marinho é Acadêmica de Direito pela Universidade Federal Fluminense - UFF/ RJ.
}

\section{Introdução}

A interação entre os paradigmas das ciências sociais e as ciências da saúde, já são citados por diversos estudos (MINAYO, 1998). Tem tornado maior a probabilidade de correlações 
inusitadas, mais próximas da realidade e, reveladoras de novas nuances da complexidade do homem e na sua forma de sentir e expressar suas reais condições de saúde e doença. A respeito da necessidade de recorrer a diferentes campos conceituais, Campilongo (1995, p.6) nos orienta que "o objetivo das diferentes ciências é construido teoricamente pelo próprio exercício da atividade científica; as diferenças entre as ciências são, antes, 'pontos de vista' e 'estratégias".

Esta forma de pensar observa os sistemas teóricos, formulados à partir de uma práxis, que se constitui das representações dos objetos. Essas representações tentam revelar as diversas manifestações do Universo, suas classificações e sistemas códigos, que dessa forma, são transmitidos e assimilados culturalmente. Em resumo, um determinado fenômeno que ocorre na Natureza, pode ser reconstruído, segundo uma lógica própria de cada indivíduo, num contexto, passando a uma forma abstrata-conceitual, onde um sentido é atribuído. Desta maneira, vão se originando os pressupostos da filosofia e da ciência.

O conceito de representações sociais, como uma busca de sentido das imagens captadas do real, é de fundamental importância para a interpretação dos significados, através dos quais, são incluídas dimensões variáveis aos fatos. A interpretação, por sua vez, possibilita redefinições da realidade, que ajudam na compreensão de aspectos pertinentes à subjetividade do homem.

No que diz respeito à saúde e à doença, quando levamos em conta o simbolismo humano, ampliamos as possibilidades de interpretação da dor e do sofrimento. $\mathrm{O}$ que nos permite uma abordagem transepistêmica, envolvendo, tanto as ciências da saúde, como as ciências humanas. Segundo Campilongo (1995. p. 10):

O campo conceitual das disciplinas que compõem a chamada área da saúde é um campo híbrido e se caráter interdisciplinar possibilita, inúmeras vezes, que se possa trabalhar com várias metodologias, as quais levam, imediatamente, à construção de novos conceitos que possam dar conta, em alguma medida, de explicações mais aproximadas.

Essa aproximação da saúde com as ciências sociais tem se destacado, graças ao estudo dos aspectos pertinentes à subjetividade e à cultura, notadamente quando se busca os significados individuais e coletivos do adoecer e da saúde. Dentro desse movimento sócio-antropológico, surge por volta de 1960, um campo novo de conhecimento, a antropologia médica, que tem por objetivo estudar as formas de incidência e distribuição das doenças, com especial enfoque na vida social, nos hábitos, costumes e etnias. Com relação a isso, Helman (2000, p. 15) nos orienta que “como campo de estudo, a antropologia médica localiza-se, algumas vezes desconfortalvelmente, na sobreposição entre as ciências naturais e sociais e retira seus 'insights' de ambos os grupos de disciplinas."

A antropologia médica, portanto, insere-se como campo de estudo, para investigar a relação entre os aspectos sócio-culturais do adoecer humano e os fenômenos biológicos a ele 
associados. Dessa maneira, promove interações entre a medicina e as ciências naturais e sociais, buscando uma compreensão histórica do comportamento humano frente à dor e ao sofrimento. $\mathrm{O}$ objetivo é a identificação de elementos da cultura que influenciem direta ou indiretamente na saúde e na doença.

Para Helman (2003, p. 13):

A formação cultural influencia a vida das pessoas pela formação de crenças, comportamentos, percepções, emoções, linguagem, religião, rituais, estrutura familiar, dieta, modo de vestir, imagem corporal, conceitos de tempo e de espaço e atitudes frente à crença, à dor e a outras formas de infortúnio- podendo, todos, ter importantes implicações para saúde e sua assistência.

Nesse sentido, a antropologia médica se preocupa, não apenas com o indivíduo doente, ou com a patologia em si mesma, mas com as interpretações e reações dos indivíduos, em estado de saúde ou de doença. Além disso, também estuda os diversos caminhos do envelhecimento humano e suas estratégias, na busca de tratamentos, de acordo com seus atributos individuais e características sócio-culturais do lugar onde vivem.

O processo de envelhecimento populacional vem aumentando no mundo, demonstrando que, em breve seremos um mundo de idosos. Os avanços da medicina têm sinalizado com a redução das taxas de morbimortalidade, o que tem proporcionado ao ser humano uma vida mais longeva.

Segundo Berger,

Apenas há cerca de vinte anos o envelhecimento se tornou uma enorme preocupação social, em nível mundial. O número elevado de idosos, fenômeno novo na história da humanidade, conseguiu unificar a opinião internacional e solicitar a atenção dos investigadores do mundo inteiro. (BERGER, 1995, p. 01)

O envelhecimento populacional despertou a atenção da Organização das Nações Unidas (ONU), que adotou a idade de 60 anos para enquadrar a pessoa na qualidade de velho ou cidadão na $3^{\text {a }}$ idade. Denominou ainda, o período que vai de 1075 a 2025 como "Era do Envelhecimento" (SCHONS, PALMA, 2000, p. 53).

No Brasil, os idosos, ou melhor, as pessoas com 60 anos ou mais, representam 8,6\% da população do País (IBGE, 2009, 2010). De acordo com o IBGE, Instituto Brasileiro de Geografia e Estatística, da década de 1990 para os anos 2000, a população de terceira idade no Brasil cresceu 17\%. O País tem hoje cerca de 20 milhões de idosos. Em 2025, esse número deve passar para 32 milhões de pessoas.

Segundo o Ministério da Saúde, as doenças do aparelho circulatório são a principal causa de mortalidade em idosos, com mais de $37 \%$ do número de mortes. As mais comuns são derrame, infarto e hipertensão arterial. Em seguida, vêm tumores e doenças do aparelho respiratório, por 
exemplo, pneumonia e DPOC (doença pulmonar obstrutiva crônica, como o enfisema e a bronquite crônica). A lista completa das doenças e suas incidências podem ser acessadas no Portal da Saúde.

"A velhice é um período de existência que está sendo cada vez mais atingido por um número substancial de pessoas neste final de século". (VASQUES, 1989, p. 01), levando-se em consideração que este crescimento não foi programado e acontece de forma desordenada, é necessário analisar suas repercussões e implicações de origem econômica, política e social.

O envelhecimento é um fenômeno extremamente complexo. De modo genérico, podemos distinguir três tipo de idosos: os que envelhecem normalmente, sem maiores alterações orgânicas e mentais, os que manifestam precocemente modificações somato-psiquicas, e os que acrescem à marcha regressiva um estado patológico (QUEIROZ, 1999, p.47). Estas reações serão definidas através de processos, que envolvem igualmente a particularidade do idoso, a família, situação sócio-econômica, grau de instrução e educação, dentre outros.

Atualmente definimos as pessoas velhas por vários termos: adulto, maduro, idoso, maior idade, melhor idade, idade feliz, terceira idade ou até mesmo "velhos", ao invés de "senhores(as), como no passado. Dentre tantas expressões, a mais aceita entre os idosos é "Terceira Idade", este termo é utilizado para indicar a faixa etária entre a vida adulta e a velhice.

Segundo Veras (1995), o Brasil é tido como um país jovem de cabelos brancos, que ainda não despertou, necessariamente, para preocupar-se com melhores condições de vida para estes que serão em breve a maioria da população e compreender que o processo de envelhecimento reduz a capacidade física dos indivíduos e não sua capacidade intelectual.

À medida que o indivíduo envelhece, sua capacidade intelectual torna-se mais aguda e mais seletiva. O intelectual idoso não diminui a sua atividade mental, o que diminui é sua capacidade física. ( p.9)

Neri (1993), entre outros autores, considera como indicadores do bem estar na velhice: " $a$ longevidade, a saúde biológica, a satisfação, o controle cognitivo, a produtividade, a eficácia cognitiva, a continuidade de papéis familiares e ocupacionais e continuidade de relações informais em grupos primários”. (p. 10). Portanto, para um indivíduo com antecedentes normais, espírito aberto e compreensivo, o envelhecimento não trará maiores problemas, assim é notório que as variáveis relacionadas a qualidade de vida, podem ter diferentes impactos sobre o seu bem-estar.

Assim, no que se refere a sociedade brasileira que atualmente conta com uma crescente porcentagem de idosos, considera-se necessários que os estudiosos possam analisar os fatores que contribuam para o envelhecer bem, enfatizando que uma velhice satisfatória "resulta da qualidade da interação entre pessoas em mudanças, vivendo numa sociedade em mudanças" (FEATHERMAN; SMITH; PETRESON, 1990 apud NERI, 1993, p.10). 
Ainda de acordo com essa autora, o que se sabe sobre uma trajetória bem sucedida do envelhecimento diz respeito às questões relacionadas a inserção social do indivíduo em sua idade madura, e suas relações entre o bem-estar, atividade religiosa e trabalho.

As diferentes variáveis como as doenças, as perdas dos papéis ocupacionais e efetivos, que têm maior probabilidade de ocorrência na velhice, podem ocasionar diferentes graus de ansiedade, dependendo da história pessoal, do nível social e dos valores de cada um. (NERI, 1993, p.10)

A sociedade, de uma forma geral, ainda deixa transparecer o preconceito com o idoso, isto evidencia-se claramente quando escutamos expressões do tipo: O idoso é lento, o idoso não aprende, velhice é doença (...), e isto sim, pode levar o idoso a perder a auto-estima enveredando ao isolamento e assim esquecendo que as pessoas de mais idade tem enorme acúmulo de saber, pronto para serem repassados. "No nosso mundo civilizado os idosos são muitas vezes vítimas de discriminação e de estereotipos que contribuem para os isolar e para os fechar em guetos" (BERGER, 1995, p.63).

"Um idoso deve manter-se ativo se quiser obter mais satisfação na vida e se quiser manter a auto-estima e conservar a saúde” (BERGER, 1995, p.104).

Dentre vários fatores que ocorrem na velhice, existe, em função da aposentadoria, a perda de convivência com os colegas de trabalho, o que leva, na maioria das vezes, o idoso a desinteressar-se pelos seus direitos de atores sociais, considerando-se desvalorizados por imposição da sociedade.

Diante desta realidade, uma das formas que o idoso encontra para continuar sobrevivendo, é o isolamento. Este, desencadeado muitas vezes pela incompreensão de familiares, por preconceito da sociedade e principalmente por falta de políticas públicas que valorizem o idoso. Tais fatores terminam por contribuir para um quadro depressivo. Segundo Veras (1995, p.12), “É preciso vencer o preconceito com a velhice e se conscientizar da necessidade de retribuir tudo o que se recebeu dos pais".

O município de Crato, Estado do Ceará, possui um grande número de idosos, que vem crescendo percentualmente, de acordo com o IBGE (2011). Entre 1980 e 2010 a população idosa cresceu 144,6\%. O mesmo censo demonstrou que também demonstrou que a expectativa de vida vem aumentando entre os idosos. Nos anos oitenta era de 62,6 anos, sendo 59,62 para os homens e 65,69 para as mulheres. Hoje passou a 72,48 anos a idade média, sendo 69,75 para os homens e 77,26 anos para as mulheres. Até 2050, a expectativa de vida poderá chegar a 81,29 anos de idade média, sendo 78,16 anos para os homens e 84,54 anos para as mulheres.

Acompanhando essa expectativa de vida, surge a necessidade de promoção de atividades para os idosos, como uma forma de prevenção de saúde. Os grupos de convivência parecem atender a algumas dessas necessidades. O objetivo do presente estudo é conhecer sobre indicadores 
de depressão na Terceira Idade, e a contribuição dos grupos de convivência na sua reinserção social, como forma preventiva da doença mental.

\section{O processo de envelhecimento humano}

Nas últimas décadas, as mudanças registradas nos níveis de mortalidade e fecundidade vem ocasionando significantes transformações no que tange a dinâmica demográfica brasileira.

Há que se ressaltar que o constante decréscimo das taxas de natalidade e o aumento da expectativa de vida das pessoas se traduzem em uma tendência demográfica de envelhecimento populacional.

Ainda no fim do século XIX e nos primórdios do século XX, os problemas relacionados à velhice-população, até então considerada minoritária, resumiam-se basicamente nos aspectos de saúde e previdência e, portanto, não chegavam a configurar-se como um "problema social". Na atualidade, porém, esta preocupação tende a afetar de maneira crescente a organização familiar, as instituições privadas e os órgãos governamentais que têm a responsabilidade direta ou indireta de atendê-la (JORDÃO NETTO, 1986).

$\mathrm{O}$ século XX, portanto, em função dos diversos fatores citados, caracteriza-se como um período importante que demandou a construção de uma nova visão acerca da velhice. A partir deste momento histórico-social foram se estabelecendo outras formas de ver e se pensar a velhice e o envelhecimento.

Neste sentido, disponibilizar uma estrutura que proporcione um envelhecimento saudável, requer mudanças estruturais, tanto no que se refere à Políticas Públicas por parte do Estado, como também propiciar uma mudança cultural na forma de se conceber a velhice, de forma que se possa abranger toda sociedade.

Portanto, para se ter uma velhice saudável é preciso se ter uma história de vida saudável. Por sua vez, a ciência vem desenvolvendo conhecimentos que possam propiciar um envelhecimento saudável. Tanto a Gerontologia, quanto a geriatria, vem contribuindo tanto no sentido de entendimento quanto de intervenção e prevenção nesta fase da vida.

Nesse sentido, convém realizarmos algumas considerações pertinentes, em torno dessas duas terminologias, conforme JORDÃO NETTO (1986), a gerontologia é uma disciplina que foi desenvolvida especialmente para o estudo da velhice de um ponto de vista mais genérico, ou seja, que engloba o ponto de vista médico, social, econômico, psicológico, etc., já a geriatria, por sua vez, é considerada um ramo específico da gerontologia, dedicado ao estudo das doenças peculiares à idade madura nos seres humanos. 
Vale salientar a importância de trabalhos diferenciados para contribuir acerca das questões relacionadas ao envelhecimento, pois ainda acredita que a troca de vivências e experiências profissionais é considerada uma das mais ricas formas de efetuar o crescimento e desenvolvimento daquilo que se convencionou chamar de ciência.

Diante das pontuações expressas, chegar aos 80 anos não é mais sonho de poucos. $\mathrm{O}$ desenvolvimento tecnológico, as melhorias no sistema de saúde, possibilitam o vislumbrar dessa realidade. É bem verdade que o acesso a esses benefícios não é suficiente; a injustiça social, no que se refere principalmente a distribuição de renda, ainda impera, principalmente nos países pobres e naqueles em desenvolvimento, gerando assim, um grande desamparo social para aqueles que necessitam das políticas públicas como meio de alcançar uma vida com mais dignidade e equidade social (trataremos especificamente deste assunto no segundo capítulo). “(...) a questão participativa alarga sobremaneira o entendimento da política social, a começar pelo reconhecimento de que nem toda política social é pública." (DEMO, 1999, p.07).

\section{O idoso e sua convivência com a solidão}

A medida que envelhecemos, os nossos familiares também tendem a procurar suas vidas de maneira mais independente. A ausência dos familiares pode levar os idosos a sentimentos de solidão. No entanto, quando ocorre a perda definitiva dessa fonte de afeto, surgem sentimentos de tristeza, abandono, depressão ou suicídio, e quanto maior for a importância da figura de ligação perdida, mais profundo será o sentimento vivenciado (PAIVA, 1992).

A solidão nos dias atuais é um dos sentimentos que mais amedrontam as pessoas, do jovem ao idoso, em uma sociedade marcada por injustiças e ameaças, sem possibilidade de assegurar um horizonte de dignidade (OLIVEIRA, 2001).

Entende-se a solidão "como um estado emocional que inclui isolamento, tristeza, apatia, insatisfação com a vida, a qual é provocada pela ausência de contatos e relacionamentos importantes, agradáveis e significativos". O que causa tal estado emocional não é o fato de a pessoa estar fisicamente sozinha, mas o de estar privada de um ou vários relacionamentos que gostaria de ter (CAPITANINI, 2000 apud NERI, 2000, p. 71)

... a tristeza das pessoas idosas não é provocada por um acontecimento ou por circunstâncias singulares, ele se confunde com o amargo e humilhante sentimento de sua inutilidade, de sua solidão no seio de um mundo que só lhes tem indiferença." (BEAUVOUR, 1990, p.14) 
Considera-se a solidão um forte sentimento encontrado na velhice. Esta, presa não como sentimento, mas como uma maneira de ser e está ligada a algumas realidades enfrentadas pelo velho, como o relacionamento com a família levando a baixa da auto-estima (BARRETO, 1992).

Conforme Wash (1995), há evidências de existir uma ligação entre contato social, apoio e longevidade, ou seja, a grande maioria das pessoas velhas que visitam seus amigos e familiares, possivelmente, vive mais do que os que raramente estabelecem contatos.

Conforme Jordão Netto (1986), a sociedade tende a limitar, desestimular ou mesmo impedir a participação das pessoas catalogadas como velhas nos processos sócio-econômicos e culturais de produção, colocando-as numa situação típica de marginalidade social, na medida em que vão erguendo contra as pessoas velhas, um número expressivo de barreiras sociais, ao mesmo tempo em que desenvolvem contra elas atitudes de preconceitos e discriminação.

Alguns antropólogos apontam dimensões possíveis na experiência de solidão. A solidão negativa que se refere ao isolamento e ao exílio social, no sentido de abandono e rejeição. A solidão existencial reflete a busca de si mesmo e o encontro consigo mesmo, a tranqüilidade espiritual e religiosa, a introspecção e revisão da vida. A solidão positiva é apontada como elemento propulsor da criatividade, e vista como freqüente em momentos de criação artística. A idéia de solidão crônica sugere patologias que podem levar a um processo destrutivo. A solidão não é um estado natural e permanente dos idosos, mas o sentimento está presente em relatos de muitos deles (NERI, 2000, p.71).

\section{O idoso e a saúde mental}

No curso do processo de envelhecimento, muitas são as doenças degenerativas e mentais que podem acometer o idoso. Das doenças que ocorrem na terceira idade, a depressão é uma das mais importantes, pois tem atingido um número cada vez maior de pessoas na terceira idade, e isto é, um problema significante ao passo que o número de idosos no Brasil vem crescendo rapidamente.

Neste sentido, quando comparamos a depressão nos idosos com as de outras faixas etárias, percebemos que, pode não haver consenso em relação a diferenças expressivas, mas não se pode revelar que estão expostos a circunstâncias específicas da idade, como por exemplo: limitações físicas, problemas na família, perda de parentes e amigos próximos, que em muitos casos são acontecimentos responsáveis pelo início da depressão no ser humano, quando somados a outros fatores como aproximação da morte e aposentadoria, a doença atinge cada vez mais um número substancial de pessoas dentro desta faixa etária, pessoas que deveriam estar livres de problemas, colhendo frutos plantados no decorrer da vida. 
A depressão é um problema de saúde de grande importância na terceira idade, não apenas pela frequiência com que acontece, mas principalmente pelas importantes conseqüências sobre o organismo. É uma facilidade confundida com outras, sendo geralmente mal orientada em nosso meio.

Caracteriza-se por um estado de sofrimento psíquico que pode causar desordem no comportamento de uma pessoa, afetando negativamente no seu modo de vida. Altera o humor e a forma como interage na sociedade. Este estado pode ser induzido por fatores biológicos, sociais e psicológicos.

A depressão é uma doença clínica como qualquer outra já conhecida, porém, com algumas especificidades, podendo surgir em qualquer momento da vida e sua duração varia, dependendo de cada caso. Apesar da doença ser comum a diferentes fases da vida, a depressão nos idosos por exemplo, vem normalmente acompanhada de outros problemas, que muitas vezes acabam mascarando a doença, além de que geralmente é vista como um fato normal nesta faixa etária, explica a psicóloga e psicoterapeuta Dra. Olga Inês Tessari, afirmando que, um dos agravos dessa situação é que muitos médicos tendem a tratar apenas os sintomas da depressão, desconsiderando que para a cura é preciso o acompanhamento psicológico.

Vale alertar que a depressão não é uma doença isolada, além do que, produz uma queda na imunidade diminuindo a resistência física às doenças. Segundo a psicóloga Débora Sievers a depressão no idoso é de difícil diagnóstico: "na medida em que ela vem arrastada, dá a impressão de que não é nada e vai passar. Aparece mais lentamente". Por este motivo vale reforçar que, em toda situação depressiva a abordagem médica deve ser muito cuidadosa, sendo necessário que se faça uma rigorosa coleta de dados pessoais, pois um exame clínico completo associado a avaliação psiquiátrica e neurológica são indispensáveis.

Um dos fatores mais preocupantes nesta problemática é que a ausência de tratamento pode levar a morte por diferentes formas, seja por suicídio (em cases de depressão extrema) ou por doenças infecciosas, ataques cardíacos e derrames.

Para o tratamento adequado da depressão é coerente evitar o preconceito, principalmente aquele relacionado a doença mental, encarando-a como qualquer outra doença, devendo buscar o atendimento especializado com o psiquiatra. $\mathrm{O}$ tratamento varia de acordo com o grau da doença; a medicação antidepressiva é importante, mas a abordagem psicológicas é fundamental, a realização de dietas apropriadas, atividades físicas e, especialmente o apoio familiar, contribuem para a eficácia do tratamento.

Contudo, o importante é saber que todos podem ser vítimas de depressão, independente da idade, resta procurar ajuda o quanto antes, pois desta forma a possibilidade de levar uma vida normal será bem maior. 


\section{O idoso e as políticas públicas para essa faixa etária}

Em decorrência das baixas taxas de fecundidade e da queda no nível de mortalidade, passa hoje o Brasil por um processo denominado "envelhecimento populacional". Temos atualmente, em nosso país, para cada 100 crianças, cerca de 20 idosos.

São homens e mulheres com direito à saúde, à habitação, ao transporte coletivo, a previdência, à cidadania e a dignidade humana. Esses cidadãos que, em muitos casos são considerados erroneamente como incapazes, cansados pelo tempo, ao final da vida, têm, ao contrário do que se pensa, uma contribuição muito grande a dar pelo acúmulo de experiências, adquiriras na sua trajetória de vida.

Da Assembléia Geral das Nações Unidas, realizada em 10 de dezembro de 1948, originouse a Declaração Universal dos direitos humanos, adotada e proclamada pela resolução $\mathrm{n}^{\circ} 217 \mathrm{~A}$ (III), o que constitui um marco importante para a história da humanidade.

O artigo II da Declaração Universal dos Direitos humanos prescreve que "toda pessoa tem capacidade para gozar os direitos e as liberdades estabelecidas nesta declaração, sem distinção de qualquer espécie, seja de raça, cor, sexo, língua, religião, opinião pública ou de outra natureza, origem nacional ou social, riqueza, nascimento, ou qualquer outra condição".

No artigo XXVI a referida declaração prescreve que,

Toda pessoa tem direito a um padrão de vida capaz de assegurar a si e à sua família, saúde e bem-estar, inclusive alimentação, vestuário, habitação, cuidados médicos e os serviços sociais indispensáveis, e direito à segurança em caso de desemprego, doença, invalidez, viuvez, velhice ou outros casos de perda dos meios de subsistência em circunstâncias fora de seu controle".

Com o objetivo de guiar e pautar as aços governamentais e as da sociedade, no que diz respeito ao cumprimento das determinações da Declaração Universal dos Direitos Humanos, foi criado no governo de Fernando Henrique Cardoso, o Programa Nacional dos Direitos Humanos que estabelece políticas públicas para proteção e promoção dos direitos humanos no Brasil.

O programa direciona iniciativas que fortalecem a atuação das organizações da sociedade civil, atribuindo-lhes uma responsabilidade clara na promoção dos direitos humanos, principalmente no que se refere à educação e à formação da cidadania.

O programa foi elaborado no período de novembro de 1995 a março de 1996, através de realização de seminários regionais, consultas por telefone e fax a uma amostra representativa de centros de direitos humanos e personalidades. Após concluído, o Programa foi apresentado e debatido na I Conferência Nacional de Direitos Humanos, promovida pela Comissão de Direitos Humanos da Câmara dos Deputados, com o apoio do Fórum das Comissões Legislativas de 
Direitos Humanos, Comissão de Direitos Humanos da OAB Federal, Movimento Nacional de Direitos Humanos, CNBB, FENAS, INESC, SERPAJ e CIMI.

No que diz respeito à Terceira Idade, este Programa estabelece como atividades a serem desenvolvidas a curto prazo:

Estabelecer prioridade obrigatória de atendimento às pessoas idosas em salas de repartições públicas e estabelecimentos bancários do país;

Facilitar o acesso das pessoas idosas a cinemas, teatros, shows de música e outras formas de lazer públicas;

Apoiar as formas regionais denominadas ações governamentais integradas, para o desenvolvimento da Política Nacional do Idoso. (PROGRAMA NACIONAL DOS DIREITOS HUMANOS)

Atividades à médio prazo:

Criar e fortalecer conselhos e organizações de representação dos idosos, incentivando sua participação nos programas e projetos governamentais de seu interesse;

Incentivar o equipamento de estabelecimentos públicos e meios de transporte de forma a facilitara locomoção dos idosos.

E atividades à longo prazo:

Generalizar a concessão de passe livre e previdência de acesso aos idosos em todos os sistemas de transporte público urbano;

Criar, fortalecer e descentralizar programas de assistência aos idosos, de forma a contribuir para sua integração à família e à sociedade e incentivar o seu atendimento no seu próprio ambiente.

Em 4 de janeiro de 1994, no governo de Itamar Franco, foi sancionada a Lei 8.842 que dispõe sobre a Política Nacional do Idoso, cria o Conselho Nacional do Idoso e dá outras providências.

$\mathrm{O}$ inciso I do Art. $3^{\circ}$ desta lei determina que "a família, a sociedade e o Estado têm o dever de assegurar ao idoso os direitos da cidadania, garantindo sua participação na comunidade, defendendo sua dignidade, bem-estar e o direito à vida”.

No capítulo IV (Das Ações Governamentais), art. 10, inciso I, alínea b), a mencionada Lei determina que "é competência dos órgãos e entidades públicas: estimular a criação de incentivos e de alternativas de atendimento ao idoso, como centros de convivência, centros de cuidados diversos, casas-lares, oficinas abrigadas de trabalho, atendimento domiciliar e outros".

No inciso II, alínea b), do mesmo artigo, a Lei determina que é competência dos órgãos e entidades públicas "prevenir, promover, proteger e recuperar a saúde do idoso, mediante programas e medidas profiláticas" e alínea g) "realizar estudos para detectar o caráter 
epidemiológico de determinadas doenças do idoso, com vistas a prevenção, tratamento e reabilitação".

No governo de Fernando Henrique Cardoso, através do Decreto no 1.948, de 3 de julho de 1996, foi regulamentada a Lei 8.842 de 4 de janeiro de 1994, dispondo sobre a Política Nacional do Idoso e dando outras providências.

Este Decreto, no artigo $9^{\circ}$, prescreve que compete ao Ministério da Saúde, em articulação com as secretarias Estaduais, Federal e Municipais, capítulo VIII:

Desenvolver e apoiar programas de prevenção, educação e promoção da Saúde do idoso de forma a: a) estimular a permanência do idoso na comunidade, junto à família, desempenhando papel social ativo, com autonomia e independência que lhe for própria; b) estimular o auto-cuidado e o cuidado informal; c) envolver a população nas ações de promoção da saúde do idoso; d) estimular a formação de grupos de auto-ajuda, de grupos de convivência, em integração com outras instituições que atuam no campo social; e) produzir e difundir material educativo sobre a saúde do idoso.

Em 1997, o então Deputado Paulo Paim (PT-RJ) apresentou à Câmara um Projeto de Lei que, após ser votado e aprovado, foi apresentado à Nação como a Lei $\mathrm{n}^{\circ} 10.741$, de $1^{\circ}$ de outubro de 2003 - O Estatuto do Idoso.

$\mathrm{O}$ art. $2^{\circ}$ da mencionada Lei prescreve que o idoso deve gozar de todos os direitos fundamentais inerentes à pessoa humana, devendo serem asseguradas a ele todas as oportunidades e facilidades para a preservação de sua saúde física e mental e sei aperfeiçoamento moral, intelectual, espiritual e social, em condições de liberdade e dignidade. No art. $3^{\circ}$ a Lei atribui à Família, à comunidade, à Sociedade e ao Poder Público, a obrigação de assegurar ao idoso, de forma prioritária a realização do direito à vida, à saúde, à alimentação, à educação, à cultura, ao esporte, ao lazer, ao trabalho, à cidadania, à liberdade, à dignidade, ao respeito e à convivência familiar e comunitária.

Em resumo, para que aconteça a aplicabilidade dessa, bem como de outras leis, faz-se necessário que ela se torne pública, que a sociedade possa apoiar-se em suas prescrições, no sentido de assegurar os seus direitos.

\section{Considerações finais}

Com o aumento da possibilidade de viver mais, por conta da evolução tecnológica e das novas descobertas a elas associada nos últimos anos, o idoso requer uma maior atenção por parte do Estado, da família, dos profissionais de saúde e de toda a sociedade. Para que cheguemos com saúde e qualidade de vida na velhice, há que haver muito investimento, seja pessoal, seja por parte do Estado. Será que há alguma vantagem em chegarmos aos 70 ou 75 anos de idade, com as 
incapacidades diversas, tais como amputações, caquexia, cegueira, feridas, entre outras enfermidades, decorrentes das complicações das doenças crônico-degenerativas, principalmente entre os mais carentes?

Provavelmente há de haver mais investimento em saúde primária, de forma a melhorar o acesso das pessoas mais carentes à saúde, através também de ações de saúde que possam levar a um envelhecer mais digno. Por sua vez, cabe ao Estado, melhorar o atendimento ao idoso, com uma Política Nacional do Idoso que realmente atenda seus anseios, revendo as questões de seguridade e aposentadorias, de maneira apropriada.

Assim, conhecer os fatores envolvidos nas dificuldades, incapacidades, internações e reinternações de pessoas idosas, nos torna mais responsáveis por implementar mudanças a médio e longo prazo, que favoreçam e possibilitem melhor qualidade de vida aos idosos.

\section{Referências:}

BRASIL. Constituição Federal de 1988, Brasília: Senado Federal, Secretaria Especial de Editoração e Publicações: Câmara dos Deputados, Coordenação de Publicações, 1989.

BRASIL. Estatuto do Idoso, Brasília: Senado Federal, Secretaria Especial de Editoração e Publicações: Câmara dos Deputados, Coordenação de Publicações, 2003.

BRASIL. Previdência Social. Idosos: Problemas e cuidados básicos. Brasília: MPAS/SAS, 1999.

BARRETO, M. L. F. Admirável Mundo Velho. São Paulo: Ártica, 1992.

BEAUVOIR, Simone de. A Velhice. Rio de Janeiro, Nova Fronteira, 1990.

BERGUER, Peter I. e LUCKMANN, Thomas. A construção social da realidade. Petrópolis. Vozes, 1985.

CAPITANINI, Marilin Elizabeth Silva. Sentimento de solidão, bem estar subjetivo e relações sociais em idosas vivendo sós. Dissertação de Mestrado. Unicamp. 2000.

CAMPILONGO, Celso Fernandes. Direito e Democracia. São Paulo: Max Limonad, 1997. 
DEMO, Pedro. Participação é conquista: noções de política social participativa. $4^{\mathrm{a}}$ edição, São Paulo, Cortez, 1999.

FEATHERMAN, D. L., SMITH, J., \& PETERSON, J. G. Successful aging in a post-retired society. 1990. Em: P. B. BALTES \& M. M. BALTES (eds.) Successful aging. Perspectives from the behavioral sciences. (pp. 50-93). Cambridge: Cambridge University Press, 1991.

HELMAN, C. G. Aspectos culturais do estresse. 2000. In C. G. Helman, Cultura, saúde e doença (pp. 262-281). Porto Alegre, RS: Artmed, 2003.

\section{IBGE - INSTITUTO BRASILEIRO DE GEOGRAFIA E ESTATÍSTICA. Censo Demográfico}

1990: Primeiros Resultados da Amostra. Disponível em $<$ http://www.ibge. net/home/estatistica/populacao/censo1990/ primeiros_resultados_ amostra /brasil/pdf/ tabela_1_1_1.pdf > Acesso em 11/03/2003.

IBGE. Indicadores sociodemográficos e de saúde no Brasil 2009. (Estudos e pesquisas. Informacão demográfica e socioeconomica, 25). Rio de Janeiro: IBGE, 2009. Disponível em $<$ http://www.ibge.gov.br/home/estatistica/pesquisas/sintese.php>.

IBGE. Pesquisa nacional por amostra de domicílios 2008 (PNAD). Um Panorama da saúde no Brasil: acesso e utilizacão dos servicos, condicões de saúde e fatores de risco e protecão à saúde: Rio de Janeiro: IBGE, 2010. Disponível: <http://www.ibge.gov.br/home /estatistica/pesquisas/sintese.php>.

MINISTÉRIO DA SAÚDE. 2000. Portal. Disponível em http://portal.saude.gov.br /portal/saude/area.cfm?id_area=153. Acesso em:

JORDÃo NETO, Antonio. A Segregação do Velho na Sociedade. São Paulo: Secretaria de Descentralização e Participação, Conselho Estadual do Idoso, 1986.

MINAYO, Maria Cecília. O desafio do conhecimento: pesquisa qualitativa em saúde. 5. ed. São Paulo: HUCITEC; Rio de Janeiro: ABRASCO,1998.

NERI A.L. Bem estar e estresse em familiares que cuidam de idosos fragilizados e de alta dependência. In NERI, A.L. (org.), Qualidade de vida e idade madura. Campinas: Papirus, 1993. 
NERI, A. L. O Desenvolvimento Integral do Homem. A Terceira Idade..São Paulo:Ano VI, No. 10, 4-15, julho de 2000.

OLIVEIRA, Érika Arantes de, PASIAN, Sonia Regina e JACQUEMIN, André. A vivência afetiva em idosos.Psicol. cienc. prof.[online]. mar. 2001, vol.21, no.1 [citado 26 Março 2009], p.68-83.

PAIVA, V. (org.) Em tempos de AIDS. São Paulo: Summus, 1992

SCHONS, Carmem Regina; PALMA, Lúcia Saccomori. Conversando com Nara Costa Rodrigues: sobre uma gerontologia social . Passo Fundo, RS: UPF, 2000

VÁZQUEZ, M. A. V. Psicossociologia del cuidado. Valência: Universidad Cardenal Herrera CEU, 2003.

VERAS, Renato et al. Terceira Idade: um envelhecimento digno para o cidadão do futuro. Rio de Janeiro: Relume Dumará: UnATI/UERJ, 1995, p.65.

Como citar este artigo (Formato ISO):

MARINHO, A.O.O.; BARROSO, M.; MARINHO, G.O. Terceira idade: características e políticas públicas associadas. Id on Line Revista de Psicologia, Julho de 2013, vol.1, n.20, p. 108-122. ISSN 1981-1189. 